\title{
O COTIDIANO, A QUEBRADA E O SONHO: A RESISTÊNCIA PELO OLHAR NA AÇÃO DE UM FOTOCOLETIVO
}

\section{EVERYDAY LIFE, QUEBRADA, AND DREAMS: RESISTANCE THROUGH GAZE IN PHOTO COLLECTIVE ACTIVISM}

\section{Daniela Palma*}

\section{RESUMO}

Este artigo propõe refletir sobre as possibilidades enunciativas de coletivos periféricos contemporâneos, com foco na experiência do DiCampana Foto Coletivo. Criado em São Paulo, em 2016, o coletivo de fotógrafos entende a sua ação na proposta de formar uma coleção de novas imagens que mostrem a periferia sem as lentes típicas que a emolduram em estereótipos pejorativos. Categorias fenomenológicas de tempo e espaço são acionadas no percurso metodológico na tentativa de compreender a formação de sonhos e memórias na fabulação fotográfica do cotidiano das quebradas. O movimento interpretativo final é o de ler a construção de um espaço biográfico para a periferia na ação política de criar uma imagística da "periferia olhada pela periferia". A prática fotográfica e ativista é, assim, compreendida como prática de self, de composição individual e coletiva.

Palavras-chave: periferia; fotoativismo; práticas de self; cotidiano; espaço biográfico.

\section{ABSTRACT}

This paper proposes to reflect on enunciative possibilities of contemporary collectives in urban peripheries in Brazil, based on the observation of DiCampana Foto Coletivo's experience. Created in São Paulo in 2016, the collective of photographers draws its action by the proposal of forming a collection of new images with potential to show the periphery without the typical lenses that frame it in pejorative stereotypes. Phenomenological categories of time and space are triggered as a methodological path in an attempt to understand the formation of dreams and memories by the photographic fabrication of an everyday life for the quebradas (neighborhoods in Brazilian urban peripheries). The final analytical approach is in the way of interpreting the construction of a biographical space for the periphery in the political action of creating an imagery of the "periphery looked at by the periphery". Thus, the photographic and activist practice is understood as practice of the self, with individual and collective composition.

Keywords: periphery; photo activism; practices of the self; everyday life; biographical space.

\footnotetext{
* Universidade Estadual de Campinas, UNICAMP, Campinas, SP, Brasil. dpalma@unicamp.br Orcid: https://orcid.org/0000-0003-2068-0624
} 


\section{1. "TEM MUITA COISA LINDA AQUI"}

Em uma postagem de Facebook, por um ex-aluno, me encantei com uma série de fotografias mostrando amplas paisagens de São Paulo, a partir de um bairro periférico da cidade: céus expressivos, pôr do sol, morros, mar de casas... Comentei sobre a beleza das vistas e o autor da postagem e das fotos me respondeu: "E tudo aqui na periferia professora... tem muita coisa linda aqui no Ângela [Jardim Ângela, zona sul da cidade de São Paulo], como a Represa de Guarapiranga". Essa fala condensa um sentimento que talvez seja comum para muitos moradores e moradoras de bairros periféricos: um amor pelo lugar onde vive, mas um amor que pode se sentir deslegitimado - como amar o bairro pobre, espaço visto mais como um "problema social" do que como um lugar de afetos?

Interpretar esse tipo de sentimento talvez seja a proposta deste artigo, que teve como estalo para sua formulação o contato com as fotografias do DiCampana Foto Coletivo. Criado em 2016, o coletivo de fotógrafos moradores de periferias da cidade de São Paulo tem como proposta formar um banco de imagens que possa "contribuir com a produção fotográfica sobre o cotidiano das centenas de periferias e favelas espalhadas pelo mundo" (DICAMPANA, s.d., s.p.). Atualmente, o coletivo tem três integrantes: Gsé Silva, José Cícero da Silva e Léu Britto, todos são fotógrafos profissionais, de formação autodidata e moradores de periferias. A maior parte das fotografias que compõem o acervo do grupo foca em bairros periféricos da cidade de São Paulo, mas há também imagens de outras cidades brasileiras e de fora do país.

O DiCampana é uma expressão recente de toda a movimentação nas periferias de São Paulo (que talvez tenha sido um fenômeno nacional), a partir de meados dos anos 1990, de valorização simbólica desses espaços e que deu corpo discursivo para novas formações de subjetividade, principalmente para os jovens das quebradas. Assim, o que se convencionou chamar de "cultura de periferia" vem sendo forjada como uma resposta da juventude pobre às formas de representação negativa, por meio de uma intensa produção cultural que oferece novos enquadramentos para o modo de vida das comunidades (ALMEIDA, 2011, 2013).

Por esse caminho, a ideia de um cotidiano periférico múltiplo e vivo, enunciado pela perspectiva de quem o habita, para além de visões chapadas sobre violência e desigualdade, ganha relevo no programa do coletivo, como afirmado em um depoimento do grupo para um blog:

Entendendo que a narrativa do nosso povo vem sendo registrada praticamente pelos mesmos meios há décadas, a proposta do DiCampana é fazer uma cobertura introspectiva e contínua do 
cotidiano das periferias através da fotografia feita por periféricos e favelados. (DESENROLA, 2017 , s.p.)

Interessa aqui pensar junto com as fotografias do DiCampana sobre a dimensão política do cotidiano. Do trecho citado, destaco a ideia de uma cobertura introspectiva, que compreendo, nos limites deste artigo, como uma prática de produção fotográfica que promove o ato de olhar para si e observar em si memórias, afetos, sonhos e pensamentos. A prática fotográfica se formula, assim, como prática de self, na ideia básica da construção de uma imagística da "periferia olhada pela periferia".

\section{TEMPO E SONHO}

O papel nuclear do cotidiano é destacado nos textos do coletivo, que definem a missão do grupo de atuar na "construção de um imaginário que contemple os múltiplos recortes da periferia - a cultura, o lazer, a rotina, a vida do nosso povo" (DICAMPANA, s.d., s.p.). Trago, dessa maneira, para este artigo, a discussão sobre o cotidiano, pautada pelo próprio coletivo e pela compreensão de que se trata de uma dimensão central para interpretar a enunciação de vozes subalternas ou dissonantes. Um olhar para as temporalidades e as espacialidades do cotidiano pode ser entendido como caminho para a constituição de lugares enunciativos, que, segundo Homi Bhabha, está diretamente ligada à abertura para a "possibilidade de outros 'tempos' de significado cultural (retroativo, prefigurativo) e outros espaços narrativos (fantasmático, metafórico)" (BHABHA, 1998, p. 248). Podemos tomar, assim, o cotidiano como um enquadre "decisivo para objetivação das categorias da diferença", conforme proposto por Gabriel Feltran, significando compreender a política de produção simultânea dessas categorias no próprio "curso da vida social contemporânea" (FELTRAN, 2017).

Nos contextos das periferias brasileiras, o "tempo histórico do sobreviver é o momento do agora" (FACINA; SILVA; LOPES, 2019, p. 19), a chave dessa compreensão é a sobrevivência, que pressupõe temporalidades em suspensão (sobreviver não permite postergação). Essa compreensão bebe na fonte de Walter Benjamin, que deu a chave para entender o tempo da "história a contrapelo", ou seja, da história dos vencidos, não como linha homogênea e vazia, na ideia evolutiva do progresso, mas um tempo vívido, "saturado de 'agoras"" (BENJAMIN, 1993, p. 229). As temporalidades periféricas no Brasil urbano contemporâneo, lidas nessa perspectiva de uma "política no momento do agora", apresentam dinâmicas nãolineares e liminares que seriam uma marca "típica das manifestações culturais de sobrevivência" naqueles contextos (FACINA; SILVA; LOPES, 2019, p. 19). 
A temporalidade de agoras é a potência para criar projeções, o que oferece a possibilidade de seguir adiante, a própria capacidade de florescer subjetivamente para quem vive em meio a violências e violações de direitos (FACINA; SILVA; LOPES, 2019, p. 24). Veena Das chama a atenção, em seus estudos sobre memórias de violência na Índia, que, nos relatos que analisou, "as ideias de esperança não eram vistas como transcendência ou fuga para um futuro diferente, mas como a capacidade de descer ao ordinário", o que a autora chama de "uma temporalidade de segundas oportunidades"1 $^{\prime 1}$ (DAS, 2007, p. 101). Então, podemos compreender essa forma política do tempo não como uma sucessão de agoras, mas algo na equivalência do que Henri Bergson (1988) chamou de duração: o tempo como processo, mas não linearidade, o tempo do eu que vive no presente por confluências de memórias do passado e antecipações de futuro. Para Bergson, a duração - em contraste com o tempo espacializado, do relógio, linear e homogêneo - é uma temporalidade do euem-devir, logo, comporta a multiplicidade e a liberdade.

Compreender o tempo como duração é essencial, então, para traçar a ideia de potencialidades resistentes do cotidiano, ou do cotidiano como temporalidade em que a esperança pode habitar. Esperança é uma forma de sonhar acordado, afirma Ernst Bloch (1986), é também uma tática de sobrevivência, em contextos como os de quem vive em periferias e favelas (FACINA; SILVA; LOPES, 2019). A esperança no desenho do que Bloch chama de sonbo diurno aponta o papel da imaginação, que pode impulsionar para a transformação; é um afeto - presente pelo futuro, a capacidade de prefigurar o que ainda-não-é.

A proposta de ação cultural do DiCampana é a de transformação; mudar imaginários sobre a periferia, para fora e por dentro, atuando na construção de uma imagística pública (e utópica) capaz de fragilizar estigmas e potencializar novas formações de subjetividades. A esperança contida nesse projeto se move utopicamente, mas a sua realização não se dá propriamente pela elaboração fotográfica de um futuro ficcionalizado, e sim por uma descida poética ao ordinário presente. Uma poética de sobrevivência, de sonho diurno e diário, figuratizada em presenças que ocupam os espaços periféricos - as ruas, os becos, as feiras, os campinhos de futebol, os bares, os muros autoconstruídos... até o céu.

A fabricação dessas poéticas de sobrevivência pode ser lida como ação tática de ressignificação simbólica dos modos de vida na periferia em meio a uma economia de representações políticas e sociais. Compreendo tática no diálogo

1. "(..) in the manner in which ideas of hope were not seen in transcendence or in escaping to a different future but in being able to descend into the ordinary by what I would call a temporality of second chances." 
com Michel de Certeau, que identifica, nos detalhes do tecido do cotidiano, pequenas operações que apontam tanto para o que Foucault compreendeu como procedimentos articulados da tecnologia disciplinar, quanto, por outro lado, o que ele próprio chamou de "maneiras de fazer", que definiriam as "mil práticas pelas quais usuários se reapropriam do espaço organizado pelas técnicas da produção sócio-cultural" (CERTEAU, 2014, p. 41). Pois as táticas, como maneiras ou artes de fazer, compõem capacidades de traçar "trajetórias indeterminadas", são um tipo de astúcia criativa dos desprestigiados, contingente, para responder aos jogos de estratégia do poder que disciplina (ou que objetiva disciplinar).

Essa ideia de trajetórias indeterminadas é tópico do tempo futuro, essa temporalidade de potência sobrevivente e revolucionária, e trabalha a imaterialidade do que ainda-não-é, da segunda chance, na matéria das linguagens: a agência criativa que molda formas linguísticas, semióticas e midiáticas; formas essas que se fazem no tempo presente das confluências (passado e futuro, tempo e espaço, poesia e narrativa, vozes múltiplas, olhares muitos...), e impulsionam para a transformação.

\section{Ensaio fotográfico 1: época de pipa}

"É época de pipa, o céu tá cheio/ quinze anos atrás eu tava ali no meio./ Lembrei de quando era pequeno, eu e os caras/ faz tempo - diz aí! - o tempo não para...". Em um ensaio sobre os Racionais MC's, Maria Rita Kehl destaca, de alguns versos de Fórmula mágica da paz (1997), o vislumbre de pipas no céu, imagem que desencadeia um breve momento de memoração. A autora chama atenção de como o universo das letras dos Racionais é marcado por um cotidiano dominado pelo real, "no sentido que a psicanálise lacaniana atribui à palavra: o indizível, o que está além da capacidade de elaboração pela linguagem, o que nos escapa sempre" (KEHL, 1999, p. 103). No entanto, naqueles versos, há um momento único de brecha para a sublimação, as pipas evocam o tempo perdido da infância, um tipo de afeto tipicamente memorialístico, e projetam ideia de futuro ("o tempo não para...") e também um "espaço virtual para a beleza" em meio ao "campo minado": "o céu cheio de pipas da periferia é uma interferência estética sobre a miséria e a recusa da desumanização que ela promove" (KEHL, 1999, p. 104).

A pipa, objeto lúdico, cheio de simbologias para quem vive ou viveu em periferias como as de São Paulo, condensa formas de memória, futuro e suspensão para o sublime. É tema de um dos ensaios fotográficos do DiCampana, "Época de pipas".

Para que algo se torne tradição, é necessário continuidade. É preciso que seja passado por gerações. Em São Paulo, durante as férias escolares, basta olhar para o céu para observar 
uma de suas mais fascinantes e coloridas heranças. Pelos ares, com força e graça, aliviando o excesso de cinza paulistano, as pipas criam há décadas um clima de beleza e tensão entre motoqueiros e fios. Nas periferias da cidade, o espetáculo é mais evidente. (...) (Apresentação do ensaio "Época de pipa", DICAMPANA, s.d., s.p.).

A pipa é o ornamento do céu na periferia, um céu que tem identidade própria justamente porque as pipas oferecem a ele um traço de memória - "fascinantes e coloridas heranças". Nas doze imagens que compõem o ensaio, é curioso observar como, em nenhuma delas, conseguimos propriamente avistar pipas voando no céu, no máximo, podemos supor sua presença (um ponto no céu?). Uma marca compositiva muito forte nesse conjunto de fotografias, que ajuda a dar um sentido de coesão, é o uso da angulação, não apenas do ângulo de câmera, mas também na pose, pelo jogo de ângulos dos olhares das pessoas fotografadas. Não me interessa aqui emprestar fórmulas esquemáticas para ler significados de ângulos e poses fotográficas. Assim, parto da própria palavra do coletivo: "seus olhos com o rosto para cima". Pipa é um objeto que faz o olhar levantar, pose-emblema do sonho, da contemplação e da insubmissão.
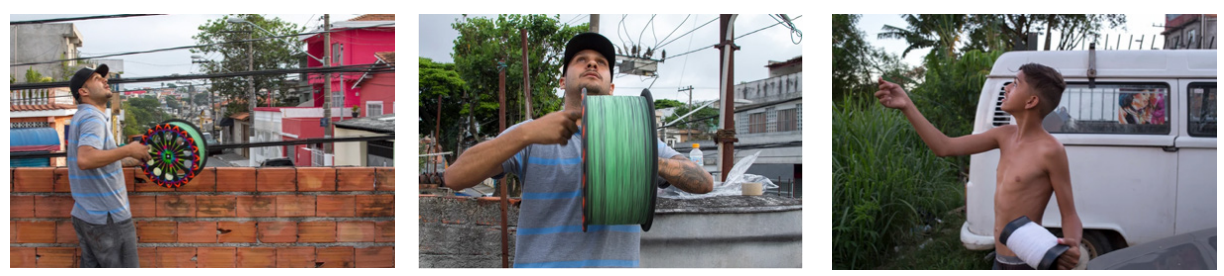

Figs. 1, 2 e 3. Olhos com rosto para cima. Ensaio "Época de pipa". DiCampana Foto Coletivo. ${ }^{2}$

Os olhos com rosto para cima olham para o que não nos é mostrado, mas o que é olhado existe no extracampo fotográfico: os olhares dos rapazes fotografados apontam para as linhas superiores do quadro e criam a presença, fotograficamente invisível, do céu enfeitado de pipa. Há uma tensão entre o real fotográfico (por contiguidade, o céu tem que estar lá, afinal é registro documental) e o artifício (o céu de pipa é inventado compositivamente pela pose fotográfica), e essa tensão possibilita o estabelecimento de uma brecha imaginativa: o que não vemos e é presença existe como fantasma e sonho. No âmbito dos sentidos representacionais, quem cria o céu de sonho são os olhares dos fotografados, que são existências individuais e coletivas, simultaneamente - a periferia que olha para céu.

2. Todas as fotos utilizadas neste texto foram extraídas de: https://www.dicampana.com/ensaios e tiveram seu uso autorizado pelos fotógrafos do coletivo. 
Se os olhos apontam para o céu, a câmera experimenta diversas angulações. Mira para a terra, para o solo, para os pés.
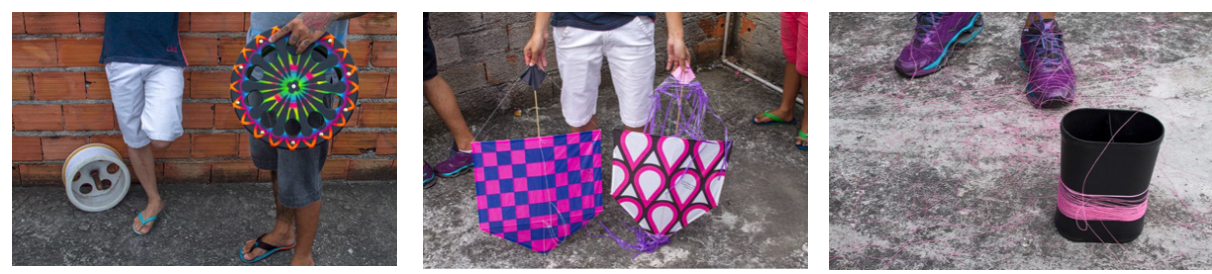

Figs. 4, 5 e 6. Mirando os pés. Ensaio "Época de pipa". DiCampana Foto Coletivo.

Pés e chão marcam visualmente essas imagens, pela angulação de câmera de cima para baixo, possibilitando, por composição (pés + chão), a formação de um sentido metafórico (território). As imagens também focam os objetos (pipas e carreteis para enovelar o cordel), que acabam por desempenhar o papel de índices de uma prática. Em outras fotos, com os ângulos mais suaves e enquadramentos mais fechados, o destaque vai para as mãos.
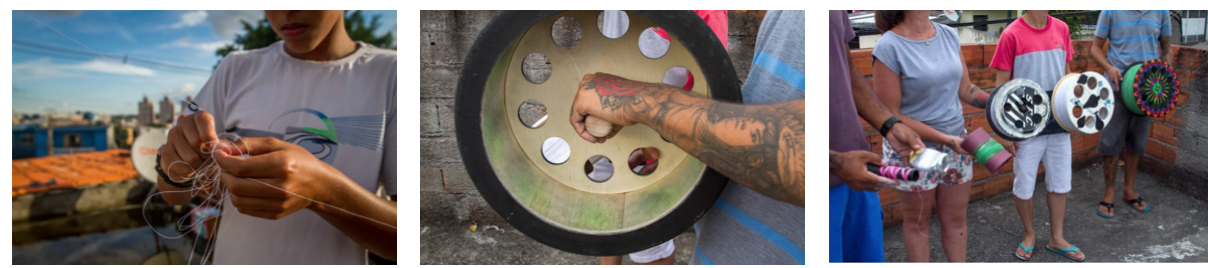

Figs. 7, 8 e 9. Mirando as mãos. Ensaio "Época de pipa". DiCampana Foto Coletivo.

Os corpos são, assim, marcados fotograficamente pela fragmentação (pés e mãos) e pela pose típica (cabeça para cima), elementos que dão desenho à própria prática. É também o corpo (os olhos) que cria o céu do lazer cotidiano e do sonho.
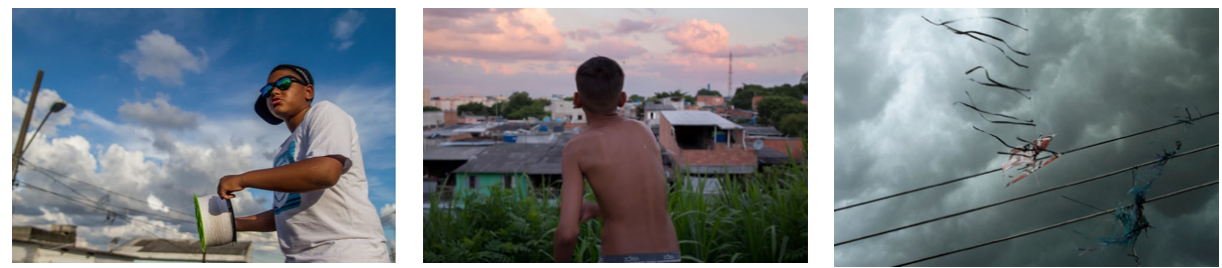

Figs. 10, 11 e 12. Aparições do céu. Ensaio "Época de pipa". DiCampana Foto Coletivo. 
Há três imagens que direcionam propriamente a câmera para o céu. $\mathrm{Na}$ primeira, um céu sobre o garoto e sua prática, pela angulação de baixo para cima (fig. 10), na seguinte, composta no ângulo reto da câmera e enquadramento panorâmico (fig. 11), neste caso, o céu é horizonte - para o garoto que empina pipa e também para nós, espectadores da fotografia. Na terceira delas (fig. 12), o céu de nuvens escuras funciona como plano de fundo na foto e a pipa vira ruína, objeto de passado, vestígio da prática: o que já foi pipa jaz enroscada nos fios elétricos, imagem que tanto pontua a paisagem periférica.

Esperança é pipa no céu.

\section{ESPAÇO, MEMÓRIA E AMOR}

Ser da quebrada. A periferia é território e serve de marcador para formações identitárias e subjetivas. É uma posição (ou um lugar que permite múltiplas posições) para sonhar (olhar pipas no céu ou inventar pipas no céu) e para lembrar ("fascinantes e coloridas heranças"; "lembrei de quando era pequeno"). Se a temporalidade como duração para compor sentidos de sonho e esperança já foi explorada no item anterior deste artigo, o foco agora aponta para a temporalidade da memória em articulação com algumas compreensões de espaço. Nessa exploração teórica, parto de duas afirmações: o tempo da memória é espaço e sua dinâmica de funcionamento é metonímica ou indiciária.

A primeira afirmação tem base em uma constatação muito simples, o tempo é fundamentalmente abstrato, logo não figurativiza em si, é preciso ser particularizado em espaços. Tempo e espaço são tomados como categorias fenomenológicas, assim, não seria o caso exatamente de definir o espaço como base em uma mera ideia de "concretude", mas principalmente como a dimensão que permite um manuseio semiótico em termos figurativos - e, em se tratando de fotografias, a fabulação temporal só é possível por meio de uma fabulação a partir do espaço de existência concreta ou física, o que não é sinônimo de real.

As imagens (ou narrativas) de passado não são propriamente "produto direto da imaginação", afirma Gaston Bachelard, "a imaginação, em suas ações vivas, nos desliga ao mesmo tempo do passado e da realidade", seu sentido é para o futuro (BACHELARD, 1978, p. 195). Assim, a memória não equivale, metodologicamente, a uma simples elaboração ficcional; quando uso a palavra fabulação, não dou a ela o sentido da produção do falso. Sobre as lembranças, pressionam-se existências mudas e, para que passem da condição da mudez à fala, o sujeito precisa fabular. Em trabalho anterior, aprendi com Carolina Maria de Jesus como as posições de 
subalternidade exigem alta carga de energia política, psicológica e criativa para os sujeitos construírem para si um "vir-a-ser histórico" (PALMA, 2017). O real do contexto social de Carolina de Jesus não lhe permitiria falar sobre as coisas do mundo, contar sua história e escrever livros, mas ela escrevia porque fabulava seu próprio lugar de enunciação e pôde, assim, criar a sua língua literária, por meio da qual narrou seus espaços concretos de existência (o barraco da favela, a casa de alvenaria, as casas de sua infância etc.).

Voltando a Bachelard, ele propôs, em seu clássico livro sobre a imaginação poética, examinar "as imagens do espaço feliz", na ideia de compor um campo de estudo de topofilias, que visaria "determinar o valor humano dos espaços de posse, espaços proibidos a forças adversas, espaços amados" (BACHELARD, 1978, p. 196). O foco de Bachelard foram os espaços de amor e felicidade, que também é o meu neste artigo, sem com isso desconsiderar que, no jogo das identidades e das políticas da desigualdade, o lugar de amor também se forma como resposta a contrapelo às representações sociais de espaços de ódio e hostilidade.

Neste caminho de uma topofilia do amor, o espaço habitado tem sentido nuclear. Sharon Zukin diferencia, em perspectiva sociológica, a paisagem de poder e a vernacular; enquanto a primeira é pensada como um arranjo dominante sobre a cidade, a segunda oferece os sentidos da cidade por quem a habita. O vernacular urbano pode incluir tanto as materialidades de prédios e ruas, quanto as relações sociais dos "desprovidos de poder", que podem atrapalhar "a expansão dos poderosos" e contestar "a expansão física e econômica destes e o espaço social para a sua auto-expressão" (ZUKIN, 2000, p. 107). Além da capacidade de contestação, a cidade vernacular implica um tipo de criatividade que consegue transformar o uso do espaço em conteúdo afetivo, permitindo a formação de memórias. É, assim, uma concepção de espaço vivido e simbolizado no próprio uso cotidiano, e é condição para a imanência das espacialidades e territorialidades nas formações identitárias e subjetivas.

Em uma abordagem mais fenomenológica, Paul Ricoeur considera que o espaço habitado é, junto com o tempo, a "condição formal de possibilidade do gesto de arquivamento", ou seja, estão na base da atividade da memória (RICOEUR, 2007 , p. 156). O espaço habitado é o terreno aberto para as nossas práticas e percepções, é dele que extraímos as marcas exteriores que adotamos como "apoios e escalas para o trabalho da memória"; temos, dessa forma, "a espacialidade corporal e ambiental inerente à evocação da lembrança" (RICOEUR, 2007, p. 156-157).

Bachelard também coloca no cerne da capacidade memorialística o espaço habitado, mas elege o lugar da felicidade primeira: "a casa natal", que mais do que 
"um protótipo de casa, é um corpo de sonho" (BACHELARD, 178, p. 207). Essa figura escolhida por Bachelard pode ser estendida geograficamente para compor o sentido de lugar de pertença - a rua, a vizinhança, o bairro, o campinho, o céu de pipa... a quebrada - e o adjetivo "natal" não precisa indicar exclusivamente o local de nascimento, mas qualquer referência espacial que forneça o sentido de uma concha de acolhimento. A "casa natal" é o lugar que oferece paz para o devaneio, sem medo de se perder de si, dá o arrimo para os pensamentos, as lembranças e os sonhos. Essa concha também representa o solo de uma necessidade fundamental humana, que Simone Weil chamou de enraizamento: "o ser humano tem uma raiz por sua participação real, ativa e natural na existência de uma coletividade que conserva vivos certos tesouros do passado e certos pressentimentos do futuro" (WEIL, 1979, p. 347).

Olhando as imagens do DiCampana como um mosaico, no movimento de rolar a tela do seu perfil no Instagram ${ }^{3}$, observo a recorrência de certas figuras que indicializam a composição de uma concha periférica de pertencimento. Crianças brincando e animais de estimação são os personagens mais frequentes, como também a presença constate de motos e bicicletas - e pipas, muitas pipas. Elementos do cotidiano doméstico vazam para o lado de fora no desenho de lugar em que os limites casa e rua são bem mais flexíveis: janelas abertas, panelas secando sobre o muro, roupas no varal, o churrasquinho na calçada, a lavagem do carro no beco, um grande bolo de aniversário sendo carregado por vizinhas...

Essas imagens nos permitem, de forma vívida, perceber a fabricação de memórias no dia a dia. A memória formada na lida do cotidiano, no nível social não institucionalizado, é de natureza comunicativa, conforme classificação apresentada por Jan Assmann (2008). Essa "prática interativa situada na tensão entre as evocações de passado por indivíduos e por grupos" pode nem ser intencionalmente memorialística, é instável, múltipla e opera por táticas e negociações (WELZER, 2008, p. 285). As fotografias do DiCampana podem ser interpretadas, dessa maneira, por esse sistema de produção de memória. Jan Assmann chama atenção que a memória opera não pela construção de metáforas, mas de metonímias; não se recorda em comparação com algo, mas a partir de algo, uma materialidade - seja o cheiro de uma madaleine, um som de sirene ou o vislumbre do céu enfeitado de pipa -, a memória resulta do contato entre "uma mente que recorda e um objeto recordatório" 4 (ASSMANN, 2008, p. 111). Rememorar é ato que se faz, assim, no

3. Disponível em: < https://www.instagram.com/dicampanafotocoletivo/>.

4. "(...) 'memory' is not a metaphor but a metonym based on material contact between a remembering mind and a reminding object". 
corpo, em um ambiente e por meio de estímulos sensoriais. Além disso, as fotografias são elas próprias objetos de memória, formam arquivos e agenciam processos futuros de recordação. A fotografia, como mídia, é objeto muito recorrente e potente em práticas de memória e de construção de self, pois é capaz de servir tanto como externalização quanto como rastro (RUCHATZ, 2008). Como externalização, forma estoque de memória fora da mente (arquivo) e também pode circular socialmente e participar das políticas de representação. Como rastro, opera não exatamente de forma representacional, mas como fantasma, presença que emana do que está ausente por meio de operações indiciárias imaginativas, incitando memórias, pensamentos e sonhos.

\section{Ensaio fotográfico 2: Copa do Mundo 2018}

O futebol é paixão nacional. (...) Ele está presente no dia a dia do brasileiro, move multidões, desperta amor e ódio. E nas periferias ele pulsa, vive nas camisetas, nas televisões dos bares, nas ruas com traves feitas de chinelos enquanto o pé descalço dribla e faz o gol, nos tantos campos da várzea, nas rodas de conversa e nos sonhos de tantos garotos e garotas. (...) Vizinhos se juntam para pintar seus rostos, pintar as ruas, armam churrasco na calçada da esquina para servir todo mundo. Camisetas azuis, verde e amarelas são vistas aos montes e durante o jogo o silêncio só é quebrado no momento do gol, que é quando explodem os gritos, vuvuzelas, fogos de artifício. Não interessa qual o time do coração de cada um, durante a copa são todos Brasil. (...) (Apresentação do ensaio "Copa do Mundo 2018", DICAMPANA, s.d., s.p.)

O ensaio sobre a Copa é composto por 15 fotografias, sobre as quais proponho pensar uma breve cartografia de topofilia do pertencimento. Para o sentido territorial, recorro à ideia pedaço, umas das categorias que José Guilherme Magnani propõe para o trabalho etnográfico urbano, como construto que fornece parâmetros de recortes e fronteiras espaciais na relação dos sujeitos com a cidade. $\mathrm{O}$ pedaço é uma categoria espacial formada a partir da observação da "cultura popular e [de] modalidades de lazer que ocupam o tempo livre dos trabalhadores, nos bairros da periferia de São Paulo" (MAGNANI, 1992, p. 196) e expressa relações de família e vizinhança; ou seja, é um delimitador espacial para sentimentos de pertencimento, funcionando como referência visível e estável.

O pedaço se faz por componentes espaciais físicos e de sociabilidade que apontam para relações de reconhecimento (quem é do pedaço e de fora dele), códigos compartilhados e lealdade. No ensaio fotográfico, o pedaço está tingido de verde, azul e amarelo; assim, um marcador espacial de identidade local é sobreposto por um marcador cromático de identidade nacional. As simbologias do local e do nacional em dia de Copa, talvez, tal qual o próprio futebol, na definição de José Miguel Wisnik, operam como línguas de "zona limiar entre tempos culturais que se entremeiam" (WISNIK, 2008, p.20) 


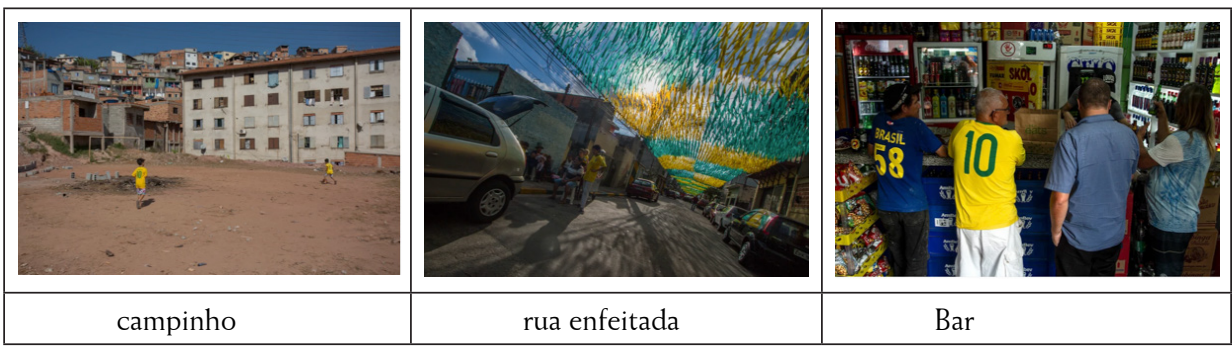

Figs. 13, 14 e 15. Um pedaço e seus pontos. Ensaio "Copa do Mundo 2018". DiCampana Foto Coletivo.

No mapa do pedaço em dia de jogo da Copa, três pontos principais definem a sua territorialidade: o campinho, as ruas enfeitadas e o bar. O campinho talvez seja um espaço arquetípico no imaginário das periferias urbanas em várias partes do mundo (WISNIK, 2008, p. 95). Localmente, é o jogo de várzea que germinou das beiras de rios paulistanos e se alastrou pelos inúmeros grotões da cidade. O campo de chão de terra e o jogo de bola simbolizam as brincadeiras, a infância, a concha primeira, como também dos "sonhos de tantos garotos e garotas", que vestem a camisa canarinho para a pelada no dia de Copa, mimetizando a partida televisiva da seleção.

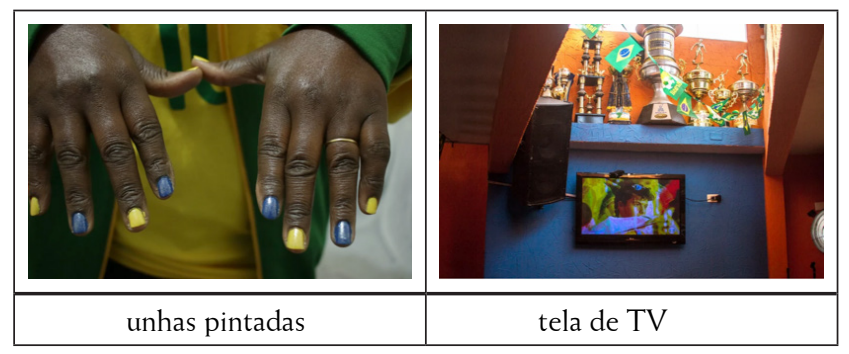

Figs. 16 e 17. No bar. Ensaio "Copa do Mundo 2018". DiCampana Foto Coletivo.

As ruas periféricas enfeitadas são o espaço do congraçamento, pintadas pela ação coletiva de vizinhos, são também o espaço da sociabilidade típica do pedaço (as reuniões na calçada, o churrasquinho, o som do carro ligado), que hibridiza o público e o privado. Por fim, o bar, ponto privilegiado dos encontros regulares e dos dias de festa. Em jogo de Copa, o bar é o local principal do encontro de corpos vestidos e pintados nas cores nacionais, de imagens televisivas, da roda de samba e da conversa entre os chegados. 
O pedaço em dia de jogo da Copa é espaço sensorialmente vívido e comporta contrastes; é figura de representação que ajuda a construir uma concha de pertencimento que fornece aos moradores da periferia um lugar para tecer memórias.

\section{UM ESPAÇO BIOGRÁFICO DA PERIFERIA}

Nas partes anteriores deste artigo, busquei pensar as possibilidades enunciativas subalternas, junto e a partir da ação e das imagens do DiCampana, por meio de categorias de tempo e espaço que trabalham na formação sonhos e memórias na fabulação do cotidiano periférico. Agora, em um movimento final, tento levar essas reflexões para o campo da constituição de narrativas, mais especificamente, das formações biográficas.

Colocando em cena o tópico biográfico, perguntas saltam: de que self estamos exatamente falando, quando apontamos para a ideia de um imaginário da periferia pela periferia? Como definir os sujeitos do cotidiano? Como pensar, a partir desse caso específico, nas articulações de selves entre autor(es), coletivo (grupo) e coletividade ("nosso povo" ou "periferias de todo o mundo")?

Agnes Heller interpreta o cotidiano como a esfera da vida de todos os seres humanos, da qual cada um deles deve participar de forma integral, em todos os aspectos da individualidade e da personalidade. A autora define a vida cotidiana como a vida do indivíduo, entendendo que o indivíduo do cotidiano é "sempre, simultaneamente, ser particular e ser genérico" (HELLER, 1985, p.20). A ideia de subjetividade e de protagonismo (para já começar a aludir ao regime da narrativa) no cotidiano é, assim, formada na tensão entre particularidade e genericidade.

No cenário geral do cotidiano das periferias brasileiras, a figura de grupos de ação político-sócio-cultural, autodesignados coletivos, aparece como agenciadora principal da formação um sujeito coletivo que contém em si multiplicidade e homogeneidade, particularidade e genericidade. Não apenas cada coletivo se forma nessa dinâmica de um uno formado de múltiplos, como existe por meio de uma cultura de "redes interperiféricas" (ALMEIDA, 2013, p. 164), que articulam coletivos para além dos limites comunitários, regionais e nacionais.

Esses grupos ou redes foram e são fundamentais nos processos que forjam o sujeito coletivo "periferia", que ganha corpo por meio de práticas e da criação de linguagens e simbologias. Esse corpo simbólico geral, a(s) cultura(s) de periferia, condensa "um conjunto de representações (...) que congrega aspectos relacionados à classe, à etnia, ao lugar de moradia e à condição de jovem na metrópole" (ALMEIDA, 2011). Também poderíamos pensar nas questões de gênero, na 
formação de um sujeito coletivo periferia, que podem ora se congraçar e ora se chocar com outros marcadores identitários - seria, assim, possível indagar se, no conjunto das imagens do DiCampana, haveria um predomínio de representações de periferia em perspectivas mais masculinas. No entanto, a proposta aqui não é a de tentar destrinchar os meandros dessas interseccionalidades, apenas tomá-las como premissa para pensar a coletividade como um sujeito que comporta em si a multiplicidade.

Especulo, agora, sobre a possibilidade da figura de um sujeito coletivo nas dimensões autoral e biográfica. Para o primeiro foco, recorro ao pesquisador Eduardo Queiroga (2017), que apresenta uma discussão sobre a caracterização da autoria coletiva em fotografia. Ele parte de um questionamento sobre a possibilidade de existir uma fotografia efetivamente coletiva, tendo em conta o histórico dessa prática, definida primeiro pela ausência de sujeito autoral, devido ao automatismo, e depois pelo autor marcadamente individualizado. Queiroga observa diversas experiências de agremiações de praticantes de fotografia (amadores ou profissionais) desde o século XIX, identificando três modelos principais: os fotoclubes, as agências e os coletivos contemporâneos. Os dois primeiros formatos, bem como algumas outras iniciativas mais singulares, seriam agrupamentos de individualidades autorais, mesmo quando havia linhas programáticas claras. Pesquisei, há tempo, a experiência de uma agência de fotógrafos operários na Alemanha de Weimar, dentro do aparato de comunicação do Partido Comunista, que tinha como objetivo criar uma estética baseada em um "olhar de classe"; mesmo com um programa de teor doutrinário, a ideia de um sujeito de classe não se converteu, na prática, em figura autoral (PALMA, 2006).

Queiroga descreve que, os coletivos contemporâneos, que aparecem a partir do início do século XXI, inauguram um jeito novo de conceber a produção fotográfica, a partir de modelos rizomáticos, que permitem mais "porosidade entre os sujeitos criadores" (QUEIROGA, 2017, p. 144). As características principais desses coletivos seriam participação ativa nas questões temáticas e estéticas; o compartilhamento potencializado pelas tecnologias digitais e redes sociais e o crédito coletivo. Essas caraterísticas marcam a prática do DiCampana; suas plataformas principais são as redes sociais, o trabalho é colaborativo e a creditação das imagens, no nome do coletivo. No entanto, outra marca muito importante na caracterização do DiCampana, em comum com coletivos de periferia, é a definição de uma cobertura temática que se baseia na identificação biográfica com seus integrantes. 
A biodata de José Cícero, um dos fotógrafos do DiCampana, no site do coletivo, abre com uma breve introdução de natureza mais biográfica que curricular: "nordestino de origem, favelado pela vivência e periférico por circunstâncias. O resto é corre, sobrevivência" (DICAMPANA, s.d., s.p.). Será possível pensar na ação do coletivo como, além de tática política, potência para as formações (auto) biográficas? Se é possível conceber a figura de um sujeito coletivo autoral, é pertinente falar em uma fabricação biográfica de caráter coletivo?

No programa do coletivo, como já citada, é expressa a proposição de mudar o imaginário sobre "a vida do nosso povo" (DICAMPANA, s.d., s.p.). Por essa sentença, o sentido de coletivo amplia-se para além do grupo de fotógrafos, é uma coletividade ampla, difusa, da qual o coletivo (grupo) é parte. O pronome nós seria capaz de produzir um sujeito enunciativo que conta a sua história? Para Benveniste, a unicidade e a subjetividade do "eu" não admitiriam a sua pluralização, então, o pronome nós não seria a "multiplicação de objetos idênticos, mas uma junção entre 'eu' e o 'não-eu', independentemente do conteúdo desse 'não-eu'" (BENVENISTE, 1966, p. 233) ${ }^{5}$. Há embutida nessa formulação de Benveniste a ideia de um sujeito centrado em si, o que, no entanto, limitaria o estudo da formação de subjetividades na esfera dos discursos políticos, mais ainda, quando se referem a contextos de práticas contemporâneas de lógicas mais rizomáticas.

Assim, o caminho aqui envereda para pensar esses fenômenos não por ferramentas de uma teoria da enunciação, mas de construtos que propõem tratar as subjetividades contemporâneas como formações narrativas. Recorro, então, a Leonor Arfuch, que oferece chaves para este breve estudo com a sua compreensão de "espaço biográfico". A autora parte da premissa de que os seres humanos são obcecados por deixar vestígios no mundo e isso se dá por uma multiplicidade de formas linguísticas, semióticas, discursivas e culturais e de modos manifestos e latentes. Esses grandes reservatórios de "formas de contar" que possibilitam que vidas se narrem e sejam narradas podem ser compreendidos na construção metafórica de um espaço biográfico, no qual o caráter de narratividade se dá não exatamente por uma composição estrutural, mas por articulação de sentidos mais ou menos dispersos. O espaço biográfico é, assim, formado por impressões, rastros, marcas e inscrições deixadas, de maneira mais ou menos deliberada, por indivíduos e grupos no tecido social, por meio de suas práticas e de seus produtos culturais. Pode, assim, ser compreendido como uma "confluência de múltiplas

5. "S'il ne peut y avoir plusieurs 'je' conçus par le 'je' même qui parle, c'est que 'nous' est, non pas une multiplication d'objets identiques, mais une jonction entre 'je' et le 'non-je', quel que soit le contenu de ce 'non-je'." 
formas, gêneros e horizontes de expectativa" (ARFUCH, 2010, p. 58), este último indicando possibilidades ativas das relações de produção, circulação e recepção.

O espaço biográfico quebra a compreensão de enunciações de estrutura una e voz centrada na composição de histórias de vidas, fundadas no mito do "eu", e propõe operar, assim, no regime da polifonia bakhtiniana, pela profusão de gêneros e pelo desenho da "posição enunciativa-dialógica em constante desdobramento em direção à outridade de si" (ARFUCH, 2010, p. 128). Mais do que oferecer parâmetros de autenticidade dessa voz de formação híbrida, o espaço biográfico propõe a "aceitação do descentramento constitutivo do sujeito enunciador", que é pensando não exatamente como uma personalidade, mas como uma "identidade narrativa".

Para Paul Ricoeur, a identidade narrativa possibilita conceber um sujeito formado por componentes narrativos e não-narrativos e permite falar em uma ipseidade, ou seja, a marca de formação de uma subjetividade revelada pelas narrativas, que pode ser tanto de um sujeito individual como de uma comunidade de indivíduos. A ipseidade do indivíduo e/ou da coletividade "constituem-se em sua identidade ao receberem tais narrativas, que se tornam para um e outro sua história efetiva" (RICOEUR, 1997, p. 425). Nessa conciliação entre indivíduo e sociedade no plano da enunciação e no tempo da narrativa, subjetividade é intersubjetividade, e o "eu" se enuncia "para e por um outro", compondo o espaço biográfico com base em protagonismos simultâneos. Arfuch chega a propor que mesmo o espaço urbano pode ser compreendido como (auto)biografia, tanto no entrelaçamento da vida de seus habitantes com o ambiente material, quanto na compreensão de que a cidade é "ponto de encontro de diversas visões, saberes, artes, ofícios, literaturas, ancoragens e errâncias, utopias e distopias" (ARFUCH, 2013, p. 1) $)^{6}$.

Um último ponto ainda importante de observar é que o espaço biográfico não apaga as políticas de diferença, adverte a autora, pois se deve considerar que "simultaneidade entre os participantes não pressupõe equivalência, nem deixa de lado a questão do poder, como também o dialogismo não se refere a um acordo tácito entre as partes: se o outro é uma diferença radical, sempre haverá diferenças particulares" (ARFUCH, 2018, p. 61) ${ }^{7}$.

6. "(...) la ciudad como punto de encuentro de diversas miradas, saberes, artes, oficios, literaturas, anclajes y errancias, utopías y distopías".

7. "(..) hablar de simultaneidad entre partícipes no supone equivalencia ni olvida la custión del poder y tampoco el dialogismo remite a um acuerdo tácito entre partes: si el outro es una diferencia radical habrá siempre diferencias particulares". 


\title{
Ensaio fotográfico 3: Medellín, Antioquia, Colômbia
}

\begin{abstract}
Através da figura do fotógrafo José, no início de outubro, o DiCampana participou do projeto "Intercâmbios Latinos", que proporcionou oito dias de vivência e trocas em algumas comunas de Medellín, Colômbia. A viagem propiciou que comunicadores e ativistas das periferias do Rio de Janeiro, São Paulo e Belo Horizonte - como Coletivo Papo Reto, os Jornais Fala Roça e Voz da Comunidade e da Redes da Maré, participassem de uma formação sobre o contexto sociopolítico da Colômbia e situação dos direitos humanos na América Latina. Em Medellín, durante três dias, o grupo visitou diversas comunas, dialogou diretamente com coletivos e organizações locais, aprenderam sobre a Colômbia com os nativos e contribuíram com histórias de suas comunidades, projetos e trabalhos que realizam no Brasil (Apresentação do ensaio "Medellín", DICAMPANA, s.d., s.p.).
\end{abstract}

A viagem à Colômbia descrita no texto foi realizada em 2018 e fez parte de um conjunto de ações para o estabelecimento de redes de coletivos de comunicação e mídia de periferias e favelas espalhadas pela América Latina (AURORA, 2018). Na página do DiCampana, há um pequeno ensaio com nove fotos realizadas nas comunas de Medellín naquela ocasião. Essa ação e o ensaio fotográfico resultante nos colocam alguns pontos para pensar a formação de uma identidade narrativa.

No programa geral do coletivo, o foco da cobertura de seus trabalhos é definido como "o cotidiano das centenas de periferias e favelas espalhadas pelo mundo", dentro de uma ação política em que o coletivo (grupo) e esse universo urbano amplificado formam o sentido de um "nós", sujeito-agente-híbridodescentrado. Destacando o ensaio de Medellín, o sujeito coletivo "periferia" exibe sua espessura transnacional, no recorte de uma identidade narrativa periférica e latino-americana. A cultura como tática para as sobrevivências pós-coloniais teria que ser transnacional e tradutória, já chamava a atenção Bhabha (1998). Esse caráter transnacional não apenas se faz por ações de deslocamento cultural, como a aqui narrada, mas é constitutivo também da própria formação das periferias locais, na intensidade histórica dos fluxos migratórios na cidade de São Paulo.

É possível pensar essa transnacionalidade local, latino-americana, pelo pulsar de uma certa experiência comum de tempo. Como especula Josefina Ludmer, a experiência de cotidiano na América Latina é formada por experiências do tempo persistente das ditaduras militares atravessado por saltos modernizadores que criam represamentos temporais e condenam a constantes repetições e retornos (LUDMER, 2010, p.28).

Nas ações de coletivos contemporâneos, as práticas de intercâmbio cultural poderiam ser entendidas como explorações moventes de desdobramento da posição enunciativa-dialógica em direção a outridades de si. A proposta de "trocas de experiências" parte de um princípio de que as experiências e os espaços não são os mesmos, a diferença está contida nas próprias ações, assim, "trocar experiências" 
alterna reconhecimentos e construção de equivalências, ou seja, embute uma prática tradutória.
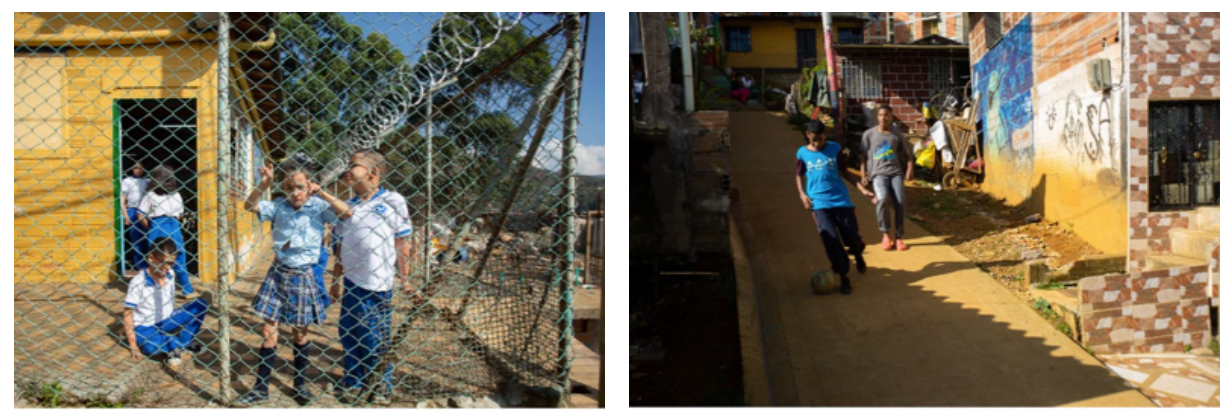

Figs. 18 e 19. Crianças: uniforme escolar e futebol. Ensaio "Medellín". DiCampana Foto Coletivo.

As crianças são personagens de destaque nessa série fotográfica, como também o são na galeria das fotografias das periferias de São Paulo. Na escola por trás da cerca e arame farpado, jogando futebol na favela... Cenas que caberiam nas paisagens urbanas daqui. Mas, será que é comum aquele tipo de uniforme escolar nas escolas públicas brasileiras? O que pulsa nessas imagens de Medellín são similaridades com pequenos toques de diferença, um quase o mesmo, mas não exatamente.
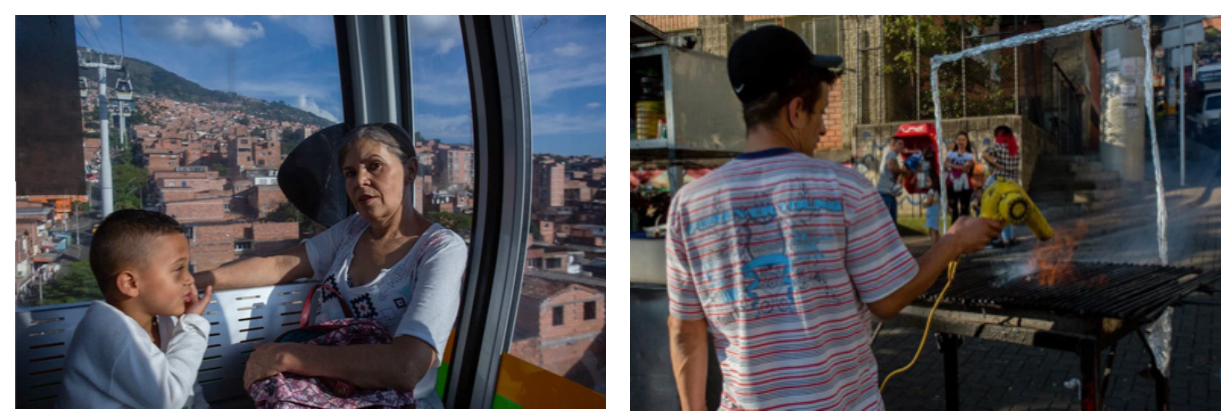

Fig. 20 e 21. Errância: no teleférico e pelas ruas. Ensaio "Medellín". DiCampana Foto Coletivo.

O fotógrafo do coletivo paulistano percorre trajetos pelas comunas de Medellín para fotografar um cotidiano de periferia na cidade colombiana. Não apenas os sentimentos de pertencimento podem produzir o espaço biográfico de cidade, mas também a potência da errância como meio de apropriação do lugar, o 
transformando em experiência, por operação similar a ler ou escutar como meio de se apropriar de um texto (ARFUCH, 2013, p. 5).

Errâncias, apropriações, pontos de diferença, traduções e uma amarração geral pelo sentimento forjado de experiência de um tempo comum constituem, assim, parâmetros para uma formação de um espaço biográfico de uma periferia latino-americana transnacional.

\section{VISLUMBRES FINAIS}

A voz, a escrita, o olhar, a recordação inesperada ou a introspecção, o que emerge de repente para logo ser esquecido, o que permanece latente em um não dizer... nesse devir incerto se desdobram as narrativas da memória, que, como a biografia, evocam - e demandam - a figura sensível da delicadeza (ARFUCH, 2018, p. 57)

Sonhos, memórias, biografias dão sentidos à vida e tornam o cotidiano habitável, se equilibrando em formas de ditos e não ditos, por isso exigem de nós, que nos propomos manuseá-los analiticamente, delicadeza. No percurso deste texto, espero ter conseguido, seguir esse conselho, de natureza poético-metodológica, de Leonor Arfuch.

O acervo de fotografias do DiCampana Foto Coletivo nos ajuda - pelo menos, me ajudou - a aprender a ver o mundo por novas lentes, sejamos nós, espectadores, parte da coletividade da periferia ou não. $\mathrm{O}$ cotidiano, lugar doce e amargo, o veneno remédio de nossas existências, é o manancial de onde se extraem as capacidades de resistência.

A resistência proposta pelo DiCampana mergulha na fonte da poesia, em uma poética que desce ao ordinário e faz do trabalho de documentação fotográfica dos lazeres, afetos e prazeres da vida diária da periferia um ato político, que condensa e cria memórias e sonhos. Essas fotografias estão aí, são arquivo existente, ou seja, são matéria de e para transformação.

E o resto é corre.

8. "La voz, la escritura, la mirada, el recuerdo súbito o la introspección, lo que emerge de pronto para ser olvidado, lo que queda latente para un no decir... en ese devenir incierto se despliegan las narrativas de la memoria, que, como la biografia, evocan -y requieren- la figura sensible de la delicadeza". 


\section{REFERÊNCIAS}

ALMEIDA, R.S. (2013). Juventude, direito à cidade e cidadania cultural na cidade de São Paulo. Revista do Instituto de Estudos Brasileiros, n. 56, p. 151-172.

ARFUCH, L. (2010). O espaço biográfico: dilemas da subjetividade contemporânea. Tradução de Paloma Vidal. Rio de Janeiro: UERJ.

ARFUCH, L. (2013). La ciudad como autobiografia. Bifurcaciones, Talca (Chile), n. 12, p.1-14.

ARFUCH, L. (2018). La vida narrada : memoria, subjetividad y política. Villa María (Argentina), Eduvim.

ASSMANN, J. (2008). Communicative and Cultural Memory. In: ERLL, A.; NÜNNING, A. (ed.). Cultural memory studies. Berlin: Walter de Gruyter. p. 109-118.

BACHELARD, G. (1978). A poética do espaço. Tradução de Joaquim José Moura Ramos et al. São Paulo: Abril Cultural.

BENJAMIN, W. (1993). Sobre o conceito da história. In: Magia e técnica, arte e política. Obras escolhidas v. 1. Tradução de Sérgio Paulo Rouanet. São Paulo: Brasiliense. p. 222-232.

BENVENISTE, E. (1966). Problèmes de linguistique générale, 1. Paris: Gallimard.

BERGSON, H. (1988). Ensaios sobre os dados imediados da consciência. Lisboa: Edições 70.

BHABHA, H. K. (1998). O local da cultura. Tradução de Myriam Ávila et al. Belo Horizonte: UFMG.

BLOCH, E. (1996). The principle of bope. Translation by Neville Plaice et al. Cambridge (USMA): The MIT Press.

CERTEAU, M. de. (2014). A invenção do cotidiano: 1. Artes de fazer. Tradução de Ephraim Ferreira Alves. Petrópolis: Vozes.

DAS, V. (2007). Life and words : violence and the descent into the ordinary. Berkeley/Los Angeles: University of California Press.

FACINA, A.; SILVA, D.N.; LOPES, A.C. (2019). Sobrevivência, linguagem e diferença: política no tempo do agora. In: (org.). Nó em pingo d'água: sobrevivência, cultura e linguagem. Rio de Janeiro: Mórula; Florianópolis: Insular. p. 15-30. 
FELTRAN, G. S. (2017). A categoria como intervalo - a diferença entre essência e desconstrução. Cadernos Pagu [online], Campinas, n. 51, e175105. DOI: https:// dx.doi.org/10.1590/18094449201700510005. Acesso: 05 ago. 2020.

HELLER, A. (1985). O cotidiano e a bistória. Tradução de Carlos Nelson Coutinho e Leandro Konder. Rio de Janeiro: Paz e Terra.

KEHL, M. R. (1999). Radicais, Raciais, Racionais: a grande fratria do rap na periferia de São Paulo. São Paulo em Perspectiva, São Paulo, v. 13, n. 3, p. 95-106, set. 1999.

LUDMER, J. (2010). Aquí América latina: Una especulación. Buenos Aires: Eterna Cadencia.

MAGNANI, J.G.C. (1992). Da periferia ao centro: pedaços \& trajetos. Revista de Antropologia, São Paulo, v. 35, p. 191-203.

PALMA, D. (2005). Um olhar de classe: a experiência da fotografia operária na Alemanha de Weimar. Lutas Sociais, São Paulo, v. 15/16, p. 104-122.

PALMA, D. (2017). As casas de Carolina: espaços femininos de resistência, escrita e memória. Cadernos Pagu [online], Campinas, n.51, e175116. DOI: https://doi.org/10. 1590/18094449201700510016. Acesso: 10 ago. 2020.

QUEIROGA, E. (2017). Quando o coletivo alcança a fotografia. Discursos Fotográficos, Londrina, v.13, n. 22, p.128-146. DOI: http://dx.doi.org/10.5433/19847939.2017v13n22p130. Acesso: 20 jul. 2020.

RICOEUR, P. (1997). Tempo e narrativa, tomo III. Tradução de Roberto Leal Ferreira. Campinas: Papirus.

RICOEUR, P. (2007). A memória, a bistória e o esquecimento. Tradução de Alain François. Campinas: Editora da UNICAMP.

RUCHATZ, J. (2008). The Photograph as Externalization and Trace. In: ERLL, A.; NÜNNING, A. (ed.). Cultural Memory Studies. Berlin: Walter de Gruyter, p. 377-388.

WEIL, S. (1979). A condição operária e outros escritos sobre a opressão. Tradução de G. G. Langlada. Rio de Janeiro: Paz e Terra.

WELZER, H. (2008). Communicative Memory. In: ERLL, A.; NÜNNING, A. (ed.). Cultural Memory Studies. Berlin: Walter de Gruyter, p. 285-298.

WISNIK, J.M. (2008). Veneno remédio: o futebol e o Brasil. São Paulo: Companhia das Letras. 
ZUKIN, S. (2000). Paisagens do século XXI: nota sobre a mudança social e o espaço urbano. In: ARANTES, A. (org.). O espaço da diferença. Campinas: Papirus. p. 104-115.

\section{Textos de jornal e internet}

ALMEIDA, R. S. (2011). Cultura de periferia na periferia. Le Monde Diplomatique Brasil, ano 5 , n. 49 , ago. 2011 , p. 36 .

AURORA (2018). Intercâmbios Latinos - jornalismo e direitos humanos. Aurora, Rio de Janeiro. Disponível em: https://aurora.jor.br/projetos/. Acesso: 01 set. 2020.

BRASIL ATUAL (2017). Sem preconceitos, fotógrafos revelam o lado invisível das periferias de São Paulo. Brasil de Fato, 16 fev. 2017. Disponível em: https://www.brasildefato. com.br/2017/02/16/sem-preconceitos-fotografos-revelam-o-lado-invisivel-dasperiferias-de-sao-paulo. Acesso: 01 ago. 2020.

DESENROLA (2017). Coletivo democratiza produção fotográfica em São Paulo com cobertura sobre cotidiano das periferias. Blog Desenrola e não enrola. Disponível em: $\quad$ https://www.desenrolaenaomenrola.com.br/territorios-criativos/coletivodemocratiza-producao-fotografica-em-sao-paulo-com-cobertura-sobre-cotidianodas-periferias. Aceso: 25 ago. 2020.

DICAMPANA (s.d.). O Coletivo. Página do Foto Coletivo DiCampana, São Paulo. Disponível em: https://www.dicampana.com/o-coletivo. Acesso: 10 mai. 2020.

Recebido: 15/9/2020

Aceito: $14 / 10 / 2020$

Publicado: 16/10/2020 